\title{
Family Doctor Contract Services and Health-Related Quality of Life Among Patients With Chronic Diseases in Rural China: What Is the Role of Socioeconomic Status?
}

\author{
Zhixian Li \\ Jie Li \\ Shandong University Cheeloo College of Medicine \\ Peipei Fu \\ Shandong University Cheeloo College of Medicine \\ Yan Chen \\ Shandong University Cheeloo College of Medicine \\ Zhengyue Jing \\ Shandong University Cheeloo College of Medicine \\ Yemin Yuan \\ Shandong University Cheeloo College of Medicine

\section{Shijun Yang} \\ Shandong University Cheeloo College of Medicine \\ Chen Yan \\ Shandong University Cheeloo College of Medicine \\ Wenjuan Li \\ Shandong University Cheeloo College of Medicine \\ Jie Li \\ Shandong University Cheeloo College of Medicine \\ Zhen Gui \\ cheeloo
}

Shandong University Cheeloo College of Medicine https://orcid.org/0000-0001-8520-5176

Chengchao Zhou ( $\square$ zhouchengchao@sdu.edu.cn )

School of Public Health, Cheeloo College of Medicine, Shandong University https://orcid.org/0000-0002-9364-3579

\section{Research}

Keywords: Family doctor contract services, Health quality of life, EQ-5D, Socioeconomic status

Posted Date: January 11th, 2021

DOI: https://doi.org/10.21203/rs.3.rs-141393/v1

License: (1) This work is licensed under a Creative Commons Attribution 4.0 International License. Read Full License 


\section{Abstract}

\section{Purpose}

The relationship between family doctor contract services (FDCS) and health-related quality of life (HRQOL) among patients with chronic diseases in rural China was unknown. This study aims to explore the relationship between status of signing on FDCS and HRQOL among patients with chronic diseases and examine whether there are differences in the relationship between different socioeconomic status (SES).

Methods

A total of 1,210 respondents were included in this study. HRQOL was measured by EQ-5D-3L. The contracting status was divided into uncontracted and contracted. Tobit regression and Logistic regression were employed to explore the association between contracting status and HRQOL. The interaction terms were included to explore the differences in the association among different SES status.

Results

Contracting with family doctors was associated with $\mathrm{HRQOL}$ (coefficient $=0.042 ; 95 \% \mathrm{Cl} 0.008$ to 0.075 ). The association was different among different socioeconomic levels that the contracting status was only associated with HRQOL in low-income $(P<0.01)$ and highly educated patients $(P<0.05)$. Compared with uncontracted patients, contracted patients reported higher ED-5D-3L utility value in the lowincome group (coefficient $=0.116 ; 95 \% \mathrm{Cl} 0.039$ to 0.194 ) and high educational attainment (coefficient $=0.236 ; 95 \% \mathrm{Cl} 0.095$ to 0.377 ) .

\section{Conclusions}

This study found a significant association between FDCS and HRQOL among chronic patients in rural Shandong, China. This relationship varied by income levels and educational attainment. The government should take efforts to formulate a variety of measures to encourage chronic patients to contract with family doctors, with special attention to people with low SES.

\section{Introduction}

With the aging of the population and the change of disease spectrum, the morbidity and mortality of chronic diseases such as hypertension, diabetes, and coronary heart disease has been on a rapid rise in the past decades. According to the World Health Statistics Report 2020, 42 million people worldwide died of chronic diseases in 2016 , accounting for about $71 \%$ of all deaths [1]. In China, chronic diseases account for more than $80 \%$ of the total 10.3 million deaths and over $70 \%$ of the burden of disease each year $[2,3]$. Previous studies showed that grassroot preventive interventions could improve the unhealthy lifestyles of people with chronic diseases. Primary health care can effectively reduce the morbidity and mortality of chronic diseases, control the condition of those with chronic diseases, and reduce the burden of chronic diseases $[4,5]$. Therefore, many developed countries have established the gatekeeper system in health care, such as the United States and the United Kingdom, in which the primary care physicians played a key role [6].

As a developing country, China has been in the process of establishing family doctor contract services (FDCS) system in health care since 2009. The long-term medical cooperation between family doctors and the residents is established by signing the contract of the service, so as to better understand the healthcare needs of the residents and improve the health status of the residents through the formulation of personalized intervention plans [7, 8]. In 2016, the Chinese government fully implemented the family doctor signing system to carry out contract services. Due to the high incidence rate and high burden of chronic diseases, patients with chronic diseases were classified as the priority population [9]. In 2017, the coverage rate of FDCS for the priority population was required to reach over $60 \%$. By 2020 , the goal of full coverage of the FDCS system will be basically achieve.

Health-related quality of life (HRQOL) is a multidimensional indicator of health that includes physical functioning, mental health, and the socially relevant roles that an individual perceives over time [10]. HRQOL can be used as an input to calculate quality-adjusted life years (QALYs), one of the most commonly reported measures of benefit in health economic evaluations. It is often used to support for public health and health policy and has become very important at the policy level [11]. However, the association between FDCS and HRQOL is not yet clear. Clarifying the relationship between FDCS and HRQOL can provide new insight for better understanding the impact of FDCS on health among the patients with chronic diseases.

Socioeconomic status (SES) depends on a combination of variables including occupation, education, income, and place of residence [12]. Studies indicated chronic disease patients with low SES have lower HRQOL [13], and there were differences in income levels in terms of the relationship of FDCS and the utilization of health services for patients with chronic diseases [14]. Other studies have demonstrated there was a differential association between chronic conditions and HRQOL across different SES positions [15]. These findings suggest the 
association between FDCS and HRQOL might be different among patients of chronic diseases with different SES, which needs to be clarified.

However, to date, there are few studies examined the possible difference in the association between FDCS and HRQOL. Thus, the present study aims to explore the relationship between FDCS and HRQOL among patients with chronic diseases and examine whether there are differences in this association across different SES status. Based on the previous findings, we hypothesized that (1) contracting with a family doctor was associated with better HRQOL; (2) there were differences in the association between FDCS and HRQOL in different SES.

\section{Methods}

\section{Study population}

The data used in this study were from the survey on FDCS that conducted in Shandong province, China in 2018. Shandong is the second most populous province in China with more than 100 million population in 2018, of which about $40 \%$ lived in rural areas. The multi-stage random sampling method was used to select the subjects. Firstly, we randomly selected three cities (Liaocheng, Zibo, and Binzhou) as study sites. Secondly, two counties were randomly selected from each sample city. Thirdly, five townships were randomly selected from each country and then six villages from each selected township were randomly selected. Finally, 16 households were randomly selected from each sample village, and only one member of a family (generally the main income earner or the elderly) was reviewed. Strict random number table sampling was used throughout the study. A total of 2,979 respondents were interviewed, of whom 1,210 patients with chronic diseases (hypertension, coronary heart disease, or diabetes) were included in the analysis.

The investigators were recruited from Shandong University. They were strictly trained before the investigation, including understanding the principles and methods of the survey, and standardizing the definition and interview skills of each study indicator, with the purpose of ensuring the quality of the survey. After the training, the investigators were given test on training effectiveness, and only those who were qualified could participate in the formal investigation. Each sampled township was also supervised by a trained supervisor who was responsible for guiding and (logical) checking survey questionnaire to ensure the accuracy and completeness of the questionnaires.

\section{Measures}

\section{Family doctor contract services}

The status of FDCS was a two-category variable. It was measured by the following yes-no question: "Did you contract with the family doctors this year?" $[16,17]$

Similar with previous studies, household income, educational attainment, and employment status were used as proxies for SES [18-20]. In this study, we tried to use the main determinants of SES (i.e. household income, educational attainment and employment status).

Educational attainment was recoded into three categories: low (primary education or below), intermediate (junior education), and high (senior education or above). According to the quartile methods, household income was classified into four categories: Q1, Q2, Q3, and Q4, from lowest to highest. We recoded employment status into two categories: unemployed and employed. Specifically, lower educational attainment, lower quartile, and unemployed status represent lower SES.

\section{Health-related quality of life}

Health-related quality of life (HRQOL) was assessed using the EQ-5D questionnaire, which consists of 5 health dimensions (mobility, selfcare, usual activities, pain/discomfort, and anxiety/depression). Each of the five dimensions has three levels indicating no problems, moderate problems or severe problems [21]. The EQ-5D-3L utility values are generated by weighting each dimension of the HRQOL, which use the time trade-off model set for the Chinese general population [22], ranging from -0.149 to 1.0, and the higher EQ-5D-3L utility values represent higher HRQOL.

\section{Covariate variable}

The marital status was divided into three categories: single, married, and others (divorced or widowed). The number of family members was divided into three categories: two and less, three to four, and more than four. The drinking status was divided into three categories, including never drinkers, current drinkers, and former drinkers. Other covariate variables include age, gender, multiple chronic diseases status, and physical exercise.

\section{Statistical analyses}


Statistical analyses were performed using Stata 14.0. The reported credible intervals (Cls) were calculated at the $95 \%$ level and $P$ values less than 0.05 were considered statistically significant. First, we used frequencies and percentages to describe the demographic characteristics of the respondents by family doctors contracting status (Yes/No). Second, independent-samples t-test was used to compare the EQ-5D-3L utility values between contracting status. Third, Tobit regression was employed to explore the association between contracting status of family doctors and EQ-5D-3L utility values. Logistic regression was preformed to explore the association between contracting status and each dimension of EQ-5D-3L. Finally, in order to explore whether there were differences in the association among different SES status (income, educational attainment, and employment status), interaction terms between contracting status and SES status were introduced in the Tobit regression models, and if the interaction terms were statistically significant in that Tobit regression model, we further stratified the regression analyze by different SES status (income, educational attainment, and employment status).

\section{Results}

\section{Socio-demographic characteristics}

Table 1 shows the demographic characteristics of the respondents. Of 1,210 patients with chronic diseases, $29.3 \%$ contracted with family doctors. The majority of the patients were never drinkers (63.8\%), female (55.9\%), married (84.0\%), and with one or two family members (60.8\%), participate in physical activities (55\%), and without multiple chronic diseases (70.7\%). In terms of SES, the vast majority of respondents were employed (69.3\%), had an education level of primary school or below (70.0\%), and had lower middle-income level (51.1\%).

\section{EQ-5D-3L values by different contracting status}

As shown in the Table 2, among the 1,210 respondents, the mean EQ-5D utility value was 0.844 ( \pm 0.177$)$. The independent-samples t-test results showed that there were significant differences in EQ-5D-3L utility value between different contracting status, the mean EQ-5D-3L utility values were higher among contracted patients than uncontracted patients, and more problems were reported in the uncontracted patients group of all dimensions.

When stratified by household income, differences in EQ-5D-3L utility values were shown across different contracting status in low-income and sub-low-income groups, whereas this difference was not found in high-income and second-high-income groups. When stratified by educational attainment, there were differences in EQ-5D-3L utility values across different contracting status in the primary school and below, high school and above age groups. Regardless of whether they were employed or not, the EQ-5D-3L utility values of different contracting status was significantly different. The EQ-5D-3L utility values of the contracted group was higher than that of the uncontracted group in all the groups which had significant differences.

\section{The relationship between family doctors contracting status and HRQOL among people with different SES}

We present the results in three models so that the association between FDCS and HRQOL could be better explored (Table 3). In Model 1, after adjusting for the age, gender, marital status, family members, multiple chronic diseases status, drinking status and sports participation, the result demonstrated that FDCS was significantly associated with the HRQOL. Compared with those who did not contract with family doctors, the EQ-5D-3L utility (coefficient $=0.042 ; 95 \% \mathrm{Cl} 0.008$ to 0.075 ) value of patients with chronic diseases who contracted with family doctors was significantly higher. When including the interaction terms between household income and contracting status into Tobit regression, model 2 shows an income difference in the association between contracting status and EQ-5D-3L utility value is significant $(P<0.05)$, Specifically, Table 4 shows that in the low-income group, EQ-5D-3L utility value of the contracted patients is higher than that of the noncontracted patients. When including the interaction terms between educational attainment and contracting status into Tobit regression, model 3 shows that there is also significant difference in educational attainment between the contracting status and EQ-5D-3L utility value $(P<0.05)$. Among the highly educated group, contracted patients showed a significantly higher EQ-5D-3L utility value compared with noncontracted patients. In addition, the relationship between contracting status and HRQOL is not modified by employment situation. Furthermore, Table 4 shows that in the low-income group, the contracted group reports fewer problems in mobility $(P=0.029 ;$ OR $=0.47)$, pain/discomfort $(P=0.005$; OR=0.43), and anxiety/depression $(P=0.027$; OR $=0.46)$ dimension of EQ-5D-3L. In the group with senior education or above, contracted patients report less problems in pain/discomfort $(P=0.001 ; 0 \mathrm{R}=0.178)$ and anxiety $/$ depression $(P=0.024$; $\mathrm{OR}=0.124$ ) dimension of EQ-5D-3L than uncontracted patients.

\section{Discussion}

The signing rate of family doctors with chronic diseases in rural areas of Shandong Province in the current study was approximately $28.9 \%$. It was far lower than the target of $60 \%$ signing rate of key groups [9], which was consistent with previous studies. It indicated that there was still a long way to push forward the FDCS among the vulnerable groups of the population in rural China. This finding also implied a need for 
studies to explore the potential barriers in FDCS among the rural patients with chronic conditions in China [23]. In addition, the signing rate among high-income group (Q4; 34.7\%) and middle-income group (Q2, Q3; 30.1\%) is higher than that among low-income group (Q1; 22.7\%). The signing rate of family doctors in patients with medium and high educational level was higher than that of patients with low educational level. The possible reason was that the patients with high income or high educational level might have better health awareness, tended to agree with advanced health service ideas, and had a higher demand of the FDCS.

The current study also demonstrated that FDCS was associated with HRQOL among patients with chronic diseases, and the contracted group reported higher HRQOL scores than the uncontracted group, which was consistent with previous studies in Turkey and Guangdong, China $[24,25,26]$. Contracting with family doctors could improve disease awareness and treatment compliance in patients with chronic diseases such as hypertension, which was useful for controlling the anxiety level of patients [19, 27-29]. Poor medication compliance, mood depression and anxiety were found to be associated with poor quality of life. We also found that the contracted group reported the lower proportion of problems in the five dimensions of HRQOL, which also proved that signing with a family doctor had a positive impact on both physiological and psychological well-being.

This study indicated that there was a significant difference in the association between contracting status and HRQOL across low-income, middle-income, and high-income groups. Specifically, the results showed that only in the low-income group, contracting status was correlated with HRQOL. One possible interpretation for this finding might be that in the middle and high-income groups, patients with chronic diseases would take the initiative to seek medical treatment and had sufficient health care resources. Whether they signed up or not would not affect their medical treatment and health care behaviors. [30] However, low-income patients were unable to obtain long-term high-quality medical care due to economic weakness and lack of medical resources. Family doctors could help them to obtain timely and effective chronic disease management services so as to improve their HRQOL [29, 31].

Our findings also showed that the HRQOL of contracted patients with high educational level was significantly different from the HRQOL of non-contracted patients with high educational level, while there was no significant difference in HRQOL between patients with middle and low levels of education. An interpretation for this finding might be that patients with chronic diseases with high educational level could better understand the relevant policies of FDCS, had higher acceptance of health knowledge [16], and had higher utilization willingness of contracted services, so they had been in better management of chronic diseases, and thus had higher EQ-5D-3L utility value. Contracted patients with low educational level may lead to low utilization rate of contracted services due to insufficient awareness of the contract content and low health literacy [32, 33].

Interestingly, we found that the employment difference in the association between contracting status and EQ-5D-3L utility value was not significant. The possible reason was that the composition of urban occupation was complex, and there were differences in the working environment and medical resources among different types of occupations. However, the composition of rural occupation was simple, most of the residents were engaged in agriculture or forestry, and there was no significant difference in the working environment.

This study is the first to comprehensively explore the relationship between FDCS and HRQOL among the Chinese rural patients with chronic diseases. It has several implications for the policy-makers. Firstly, the government should focus on the HRQOL of rural patients with chronic diseases and increase the rate of signing family doctors. Based on the existing local health resources, the government should improve the service quality and enhance the residents' trust in the clinics. In view of the priority population, health management should be strengthened to meet personalized health needs, so as to improve the enthusiasm of patients to contract with family doctors. Secondly, our findings confirm the importance of accounting for SES when evaluating the effectiveness of FDCS, so the local government should develop a targeting signing plan for different subpopulation to reduce health inequalities.

Our study has several limitations. First, the cross-sectional data used in this study does not allow determining whether the associations detected reflect a causal relationship, and a longitudinal design is needed in the future study. Second, we only included patients with hypertension, diabetes, and heart disease in the study, the types of chronic diseases involved were limited, and the severity and duration of chronic diseases were not carefully divided, which would be gradually supplemented in the follow-up study.

\section{Conclusions}

This study demonstrated a significant association between FDCS and HRQOL among the patients with chronic diseases in rural China, and there were differences in this relationship among patients with different SES levels. Compared with non-contracted patients, contracted patients reported significantly higher HRQOL scores in low-income or high educational level patients. The government should take efforts to increase the signing rate of family doctor services in rural patients with chronic diseases in particular by encouraging the subgroup of low socio-economic status to actively sign up and use family doctor services, so as to improve HRQOL. 


\section{Declarations}

\section{Ethics approval and consent to participate}

The Ethical Committee of Shandong University reviewed and approved the study protocol. All participants gave their informed written consent for participation prior to the face-to-face interview.

\section{Consent for publication}

Not applicable.

\section{Availability of data and materials}

Not applicable.

\section{Competing interests}

All authors declare no conflict of interest.

\section{Funding}

This study was supported by the National Science Foundation of China (71774104, 71974117,and 71473152), the China Medical Board (16257), Cheeloo Youth Scholar Grant, Shandong University (IFYT1810, IFYT18032, IFYT181031) and NHC Key Laboratory of Health Economics and Policy Research (NHC-HEPR2019002, NHC-HEPR2019001).

\section{Authors' contributions}

Conceptualization, Writing-review and editing, Funding Acquisition, Supervision: Chengchao Zhou; Methodology: Jie Li, Yan Chen, Zhengyue Jing; Formal analysis and investigation: Peipei Fu, Yemin Yuan, Shijun Yang, Chen Yan, Wenjuan Li, Jie Li, Zhen Gui; Investigation, Writing original draft preparation: Zhixian Li.

\section{Acknowledgements}

Not applicable

\section{References}

1. World Health Organization. (2020). World health statistics 2020: monitoring health for the SDGs, sustainable development goals.

2. World Bank. (2011) Toward a Healthy and Harmonious Life in China: Stemming the Rising Tide of Non-Communicable Diseases.

3. Joanne, E. J., Gauden, G., Colin, T., \& Robert, B. (2005). Chronic diseases 2: preventing chronic diseases: taking stepwise action. The Lancet, 366, 1667-1671.

4. Reynolds, R., Dennis, S., Hasan, I., Slewa, J., Chen, W., \& Tian, D., et al. (2018). A systematic review of chronic disease management interventions in primary care. BMC Family Practice, 19(1), 11.

5. Barbara S, Leiyu S, James M. (2010) Contribution of primary care to health systems and health. Milbank Q, 83(3):457-502

6. Pedersen, K. M., Andersen, J. S., \& Søndergaard, J. (2012). General practice and primary health care in Denmark. The Journal of the American Board of Family Medicine, 25(Suppl 1), S34-S38.

7. Bowman, M. A., \& Neale, A. V. (2013). Family physicians improve patient health care quality and outcomes. Journal of American Board of Family Medicine, 26(6), 617-619.

8. Lam, C. L. (2016). The role of the family doctor in the era of multi-disciplinary primary care. Family Practice, 33(5), 447.

9. National Health and Family Planning Commission. (2016) Guideline on promoting family doctor contract service, vol. 1.

10. The Centers for Disease Control and Prevention. (2018). Health-related Quality of Life. Retrieved October 31, 2018 from https://www.cdc.gov/hrqol/

11. McCaffrey, N., Kaambwa, B., Currow, D. C., \& Ratcliffe, J. (2016). Health-related quality of life measured using the EQ-5D-5L: South Australian population norms. Health and quality of life outcomes, 14(1), 133.

12. Grotto, I., Huerta, M., \& Sharabi, Y. (2008). Hypertension and socioeconomic status. Current Opinion in Cardiology, 23(4), 335-9. 
13. Mielck, A., Reitmeir, P., Vogelmann, M., \& Leidl, R. (2013). Impact of educational level on health-related quality of life (HRQL): results from Germany based on the EuroQol 5D (EQ-5D). The European Journal of Public Health, 23(1), 45-49.

14. Hongmei L, Yuan G, Qi M, Anqi C, \& Aijun X. (2019). Study on the Impact of Family Doctor Contracting Service on Health Service Utilization of Chronic Patients. Health Economics Research, 036(011), 38-40,43. (Chinese)

15. Stafford, M., Soljak, M., Pledge, V., \& Mindell, J. (2012). Socio-economic differences in the health-related quality of life impact of cardiovascular conditions. The European Journal of Public Health, 22(3), 301-305.

16. Zhao, Y., Lin, J., Qiu, Y., Yang, Q., Wang, X., Shang, X., \& Xu, X. (2017). Demand and signing of general practitioner contract service among the urban elderly: a population-based analysis in Zhejiang Province, China. International Journal of Environmental Research and Public Health, 14(4), 356.

17. Liu, Z., Tan, Y., Liang, H., Gu, Y., Wang, X., \& Hao, Y., et al. (2019). Factors Influencing Residents' Willingness to Contract With General Practitioners in Guangzhou, China, During the GP Policy Trial Phase: A Cross-Sectional Study Based on Andersen's Behavioral Model of Health Services Use. Inquiry: The Journal of Medical Care Organization, Provision and Financing, 56.

18. Falagas, M. E., Zarkadoulia, E. A., Pliatsika, P. A., \& Panos, G. (2008). Socioeconomic status (SES) as a determinant of adherence to treatment in HIV infected patients: a systematic review of the literature. Retrovirology, 5(1), 1-12.

19. Institute of Medicine (US) Committee on Environmental Justice. (1999). Toward environmental justice: research, education, and health policy needs.

20. Winkleby, M. A., Jatulis, D. E., Frank, E., \& Fortmann, S. P. (1992). Socioeconomic status and health: how education, income, and occupation contribute to risk factors for cardiovascular disease. American journal of public health, 82(6), 816-820.

21. Szende, A., G., O., T., A. (2007). EQ-5D Value Sets: inventory, comparative review and user guide. Springer.

22. Kulkayeva, G., Harun-Or-Rashid, M., Yoshida, Y., Tulebayev, K., \& Sakamoto, J. (2012). Cardiovascular disease risk factors among rural Kazakh population. Nagoya Journal of Medical science, 74(1-2), 51.

23. Yaoqin W, Hongmei L, Anqi C, et al. Study on signing status and influencing factors of the family doctor service for residents-taking Jiangsu Province as an example. Modern Preventive Medicine, (4):631-634. (Chinese)

24. Göktas, O., Gül, Ö., Ö., \& Ertürk, E. (2016). Changes in the management of type 2 diabetic patients in family medicine practices in the Bursa region. Primary Care Diabetes, 11(2), 178-183.

25. Xiaoqin C, Weibo L. (2020). The Effect of Applying Family Doctor's Contract Service to Community Hypertension Patients and Its Influence on Their Quality of Life. Chinese and Foreign Medical Research, 18(14):175-177. (Chinese)

26. Xiaohua L, Suiting Mai, Guiqin Z. (2018). The role of family physician service health education intervention in improving the treatment effect of type 2 diabetes patients in community. Chronic Pathematology J., 19(03):349-351. (Chinese)

27. Yong W. (2018). Influence of family physician contract service on treatment compliance of patients with chronic diseases. Chronic Pathematology J., 19(01):44-45. (Chinese)

28. Cupples, M., \& Heron, N. (2016). What to do after cardiac rehabilitation programs: the role of the general practitioner in cardiovascular prevention. Monaldi Archives for Chest Disease, 86(1-2).

29. Sun, X., Tan, X., Zhu, Y., Chen, W., Zhou, Z., Liu, J., \& Huang, W. (2017). Efficacy of a type 2 diabetes self-management model with family doctor team support in southern China: a randomised controlled trial. The Lancet, 390, S8.

30. Piotrowska, D. E., Pędziński, B., Jankowska, D., Huzarska, D., Charkiewicz, A. E., \& Szpak, A. S. (2018). Socio-economic inequalities in the use of dental care in urban and rural areas in Poland. Annals of Agricultural and Environmental Medicine, 25(3), 512-516.

31. Shuo C. (2018). Research on Basic Health Status of Low-income Population. Health Economics Research, (12):72-75. (Chinese)

32. Manxiu N, \& Pingping Y. (2016). Analysis on the rural elderly chronic patient's seeking healthcare behavior and its influencing factors: Empirical analysis based on CHARLS Data. Chinese Journal of Health Policy, (5), 35-41. (Chinese)

33. Sule, S. S., ljadunola, K. T., Onayade, A. A., Fatusi, A. O., Soetan, R. O., \& Connell, F. A. (2008). Utilization of primary health care facilities: lessons from a rural community in southwest Nigeria. Nigerian Journal of Medicine Journal of the National Association of Resident Doctors of Nigeria, 17(1), 98-106.

\section{Tables}

Table1 Basic characteristics of FDCS among patients with chronic diseases in rural Shandong, China, 2018 


\begin{tabular}{|c|c|c|c|c|}
\hline \multirow[t]{2}{*}{ Characteristic } & \multirow[t]{2}{*}{$N(\%)$} & \multicolumn{2}{|c|}{ Contracting status } & \multirow[t]{2}{*}{$P$-value } \\
\hline & & Yes (\%) & No (\%) & \\
\hline Observations[\%] & $1210(100 \%)$ & $355(29.3)$ & 855 (70.7) & \\
\hline Age (Years) & & & & 0.086 \\
\hline$\leq 70$ & $906(74.9)$ & $254(28.0)$ & $652(72.0)$ & \\
\hline$>70$ & $304(25.1)$ & $101(33.2)$ & $203(66.8)$ & \\
\hline Gender & & & & 0.003 \\
\hline Male & $534(44.1)$ & $180(33.7)$ & $354(66.3)$ & \\
\hline Female & $676(55.9)$ & $175(25.9)$ & $501(74.1)$ & \\
\hline Educational attainment & & & & 0.000 \\
\hline Primary education or below & $798(70.0)$ & $205(25.7)$ & $593(74.3)$ & \\
\hline Junior education & $298(24.6)$ & $100(33.6)$ & $198(66.4)$ & \\
\hline Senior education or above & $114(9.4)$ & $50(43.9)$ & $64(56.1)$ & \\
\hline Household income ${ }^{a}$ & & & & 0.012 \\
\hline Q1 & $309(25.5)$ & $70(22.7)$ & $239(77.4)$ & \\
\hline Q2 & $309(25.5)$ & $93(30.1)$ & $216(69.9)$ & \\
\hline Q3 & $295(24.4)$ & $89(30.2)$ & $206(69.8)$ & \\
\hline Q4 & $297(24.6)$ & $103(34.7)$ & $194(65.3)$ & \\
\hline Multiple chronic diseases & & & & 0.055 \\
\hline No & $855(70.7)$ & $237(27.7)$ & $618(72.3)$ & \\
\hline Yes & $355(29.3)$ & $118(33.2)$ & $237(66.8)$ & \\
\hline Employment status & & & & 0.058 \\
\hline Unemployed & $372(30.7)$ & $123(33.1)$ & $249(66.9)$ & \\
\hline Employed & $838(69.3)$ & $232(27.7)$ & $606(72.3)$ & \\
\hline Drinking status & & & & 0.000 \\
\hline Never drinkers & 772 (63.9) & $194(25.1)$ & 578 (74.9) & \\
\hline Former drinkers & $155(12.8)$ & $54(34.8)$ & $101(65.2)$ & \\
\hline Current drinkers & $282(23.3)$ & $106(37.6)$ & $176(62.4)$ & \\
\hline Physical exercise & & & & 0.000 \\
\hline No & $544(45.0)$ & $122(22.4)$ & $422(77.6)$ & \\
\hline Yes & $666(55.0)$ & $233(35.0)$ & $433(65.0)$ & \\
\hline Marital status & & & & 0.336 \\
\hline Single & $15(1.2)$ & $3(20)$ & $12(80.0)$ & \\
\hline Married & 1017 (84.1) & 307 (30.2) & $710(69.8)$ & \\
\hline Others ${ }^{b}$ & $178(14.7)$ & 45 (25.3) & $133(74.7)$ & \\
\hline Family members & & & & 0.781 \\
\hline $1 \sim 2$ & $604(49.9)$ & $177(29.3)$ & $427(70.7)$ & \\
\hline $3 \sim 4$ & $293(24.2)$ & $90(30.7)$ & $203(69.3)$ & \\
\hline$\geq 5$ & $313(25.9)$ & 88 (28.1) & 225 (71.9) & \\
\hline
\end{tabular}


Note: FDCS: family doctor contract services.

a Q1 was the poorest and Q4 was the richest.

${ }^{b}$ Others include those who are divorced and widowed.

Table 2 Observed utility values of EQ-5D-3L of chronic patients by contracting status and household income in rural Shandong, China, 2018 


\begin{tabular}{|c|c|c|c|c|c|c|}
\hline \multirow[t]{2}{*}{ Characteristics } & \multirow[t]{2}{*}{ Mean \pm SD ${ }^{a}$} & \multicolumn{5}{|c|}{ EQ-5D-3L (\%) ${ }^{b}$} \\
\hline & & Mo & SC & UA & PD & $A D$ \\
\hline Total & $0.844 \pm 0.177$ & 24.9 & 11.9 & 24.5 & 52.5 & 22.3 \\
\hline \multicolumn{7}{|c|}{ Contracting status ${ }^{c}$} \\
\hline No & $0.831 \pm 0.006$ & 28.1 & 13.9 & 27.6 & 54.7 & 24.3 \\
\hline Yes & $0.875 \pm 0.007^{\star \star \star}$ & 17.2 & 7.0 & 16.9 & 47.3 & 17.5 \\
\hline \multicolumn{7}{|c|}{ Household income } \\
\hline \multicolumn{7}{|l|}{ Q1 } \\
\hline No & $0.775 \pm 0.013$ & 38.9 & 21.8 & 37.7 & 65.3 & 32.2 \\
\hline Yes & $0.860 \pm 0.019^{\star *}$ & 22.9 & 10.0 & 25.7 & 45.7 & 17.1 \\
\hline \multicolumn{7}{|l|}{ Q2 } \\
\hline No & $0.823 \pm 0.012$ & 30.6 & 15.3 & 28.7 & 56.0 & 25.5 \\
\hline Yes & $0.872 \pm 0.014^{\star}$ & 17.2 & 7.5 & 18.3 & 47.3 & 19.4 \\
\hline \multicolumn{7}{|l|}{ Q3 } \\
\hline No & $0.859 \pm 0.011$ & 20.4 & 9.7 & 22.3 & 51.5 & 19.4 \\
\hline Yes & $0.881 \pm 0.014$ & 16.9 & 6.7 & 19.1 & 46.1 & 13.5 \\
\hline \multicolumn{7}{|l|}{ Q4 } \\
\hline No & $0.877 \pm 0.011$ & 20.1 & 7.2 & 19.6 & 43.8 & 18.6 \\
\hline Yes & $0.883 \pm 0.012$ & 13.6 & 4.9 & 7.8 & 49.5 & 19.4 \\
\hline \multicolumn{7}{|c|}{ Education attainment } \\
\hline \multicolumn{7}{|c|}{ Primary education or below } \\
\hline No & $0.809 \pm 0.185$ & 32.4 & 16.9 & 32.0 & 60.0 & 28.2 \\
\hline Yes & $0.844 \pm 0.149^{\star}$ & 22.9 & 9.8 & 20.5 & 56.6 & 22.0 \\
\hline \multicolumn{7}{|l|}{ Junior education } \\
\hline No & $0.883 \pm 0.153$ & 18.2 & 6.6 & 16.7 & 42.9 & 13.6 \\
\hline Yes & $0.904 \pm 0.115$ & 11.0 & 3.0 & 12.0 & 42.0 & 15.0 \\
\hline \multicolumn{7}{|c|}{ Senior education or above } \\
\hline No & $0.869 \pm 0.181$ & 18.8 & 9.4 & 20.3 & 43.8 & 21.9 \\
\hline Yes & $0.942 \pm 0.118^{\star}$ & 6.0 & 4.0 & 12.0 & 20.0 & 4.0 \\
\hline \multicolumn{7}{|c|}{ Employment status } \\
\hline \multicolumn{7}{|l|}{ Unemployed } \\
\hline No & $0.765 \pm 0.204$ & 42.6 & 24.1 & 41.8 & 68.6 & 29.7 \\
\hline Yes & $0.842 \pm 0.160^{\star \star \star}$ & 30.1 & 12.2 & 23.6 & 51.2 & 21.9 \\
\hline \multicolumn{7}{|l|}{ Employed } \\
\hline No & $0.858 \pm 0.162$ & 22.1 & 9.7 & 21.8 & 49.0 & 22.1 \\
\hline Yes & $0.893 \pm 0.127^{\star \star \star}$ & 10.3 & 4.3 & 13.4 & 45.3 & 15.1 \\
\hline
\end{tabular}

Note: HRQOL: health-related quality of life; MO: mobility, SC self-care; UA: usual activity; PD: pain/discomfort; AD: anxiety/depression. 
$P$-values with statistical significance: ${ }^{\star} P<0.05,{ }^{\star \star} P<0.01,{ }^{\star \star \star} P<0.001$.

a Observed EQ-5D-3L utility values; SD: standard deviation.

b Observed frequency (\%) of "have problems" in EQ-5D-3L dimensions.

${ }^{c}$ Independent-samples t-test was used to compare the EQ-5D utility values between contracting status.

Table 3 The relationship between contracting status and HRQOL among chronic patients with different SES in rural Shandong, China, 2018 


\begin{tabular}{|c|c|c|c|c|c|c|c|c|c|}
\hline \multirow[t]{2}{*}{ Characteristic } & \multicolumn{3}{|c|}{ Model 10no interaction } & \multicolumn{3}{|c|}{ Model 2 Income $\times$ contracting status } & \multicolumn{3}{|c|}{ 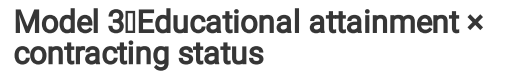 } \\
\hline & $\begin{array}{l}P \\
\text { value }\end{array}$ & Coefficient & $95 \% \mathrm{Cl}$ & $\begin{array}{l}P \\
\text { value }\end{array}$ & Coefficient & $95 \% \mathrm{Cl}$ & $\begin{array}{l}P \\
\text { value }\end{array}$ & Coefficient & $95 \% \mathrm{Cl}$ \\
\hline \multicolumn{10}{|l|}{$\begin{array}{l}\text { Contracting } \\
\text { status }\end{array}$} \\
\hline No & & Ref & & & Ref & & & Ref & \\
\hline Yes & 0.013 & 0.042 & $(0.008,0.075)$ & 0.862 & -0.006 & $(-0.069,0.057)$ & 0.001 & 0.174 & $(0.068,0.281)$ \\
\hline \multicolumn{10}{|l|}{$\begin{array}{l}\text { Household } \\
\text { income }\end{array}$} \\
\hline Q1 & & Ref & & & Ref & & & Ref & \\
\hline Q2 & 0.649 & 0.010 & $(-0.033,0.053)$ & 0.366 & 0.022 & $(-0.026,0.071)$ & 0.571 & 0.012 & $(-0.031,0.055)$ \\
\hline Q3 & 0.085 & 0.040 & $(-0.006,0.086)$ & 0.014 & 0.064 & $(0.013,0.114)$ & 0.089 & 0.039 & $(-0.006,0.085)$ \\
\hline Q4 & 0.014 & 0.059 & $(0.012,0.107)$ & 0.001 & 0.090 & $(0.037,0.143)$ & 0.010 & 0.062 & $(0.015,0.109)$ \\
\hline \multicolumn{10}{|l|}{$\begin{array}{l}\text { Educational } \\
\text { attainment }\end{array}$} \\
\hline $\begin{array}{l}\text { Primary } \\
\text { education or } \\
\text { below }\end{array}$ & & Ref & & & Ref & & & Ref & \\
\hline $\begin{array}{l}\text { Junior } \\
\text { education }\end{array}$ & 0.000 & 0.068 & $(0.030,0.105)$ & 0.000 & 0.069 & $(0.031,0.106)$ & 0.001 & 0.077 & $(0.032,0.121)$ \\
\hline $\begin{array}{l}\text { Senior } \\
\text { education or } \\
\text { above }\end{array}$ & 0.004 & 0.084 & $(0.027,0.141)$ & 0.002 & 0.088 & $(0.031,0.145)$ & 0.393 & 0.031 & $(-0.040,0.101)$ \\
\hline \multicolumn{10}{|l|}{ Gender } \\
\hline Male & & Ref & & & Ref & & & Ref & \\
\hline Female & 0.019 & -0.052 & $(-0.096,-0.008)$ & 0.029 & -0.049 & $(-0.093,0.005)$ & 0.017 & -0.053 & $(0.097,-0.010)$ \\
\hline \multicolumn{10}{|l|}{ Age } \\
\hline$\leq 70$ & & Ref & & & Ref & & & Ref & \\
\hline$>70$ & 0.177 & 0.026 & $(-0.012,0.066)$ & 0.247 & 0.023 & $(-0.016,0.062)$ & 0.168 & 0.027 & $(-0.011,0.066)$ \\
\hline \multicolumn{10}{|l|}{$\begin{array}{l}\text { Multiple } \\
\text { chronic } \\
\text { diseases }\end{array}$} \\
\hline No & & Ref & & & Ref & & & Ref & \\
\hline Yes & 0.000 & -0.069 & $(-0.101,-0.037)$ & 0.000 & -0.070 & $(-0.102,-0.038)$ & 0.000 & -0.071 & $(-0.103,-0.039)$ \\
\hline \multicolumn{10}{|l|}{$\begin{array}{l}\text { Employment } \\
\text { status }\end{array}$} \\
\hline Unemployed & & Ref & & & Ref & & & Ref & \\
\hline Employed & 0.000 & 0.099 & $(0.064,0.133)$ & 0.000 & 0.099 & $(0.065,0.133)$ & 0.000 & 0.100 & $(0.066,0.134)$ \\
\hline \multicolumn{10}{|l|}{$\begin{array}{l}\text { Drinking } \\
\text { status }\end{array}$} \\
\hline $\begin{array}{l}\text { Never } \\
\text { drinkers }\end{array}$ & & Ref & & & Ref & & & Ref & \\
\hline $\begin{array}{l}\text { Former } \\
\text { drinkers }\end{array}$ & 0.127 & -0.042 & $(-0.096,0.012)$ & 0.151 & -0.039 & $(-0.093,0.014)$ & 0.123 & -0.043 & $(-0.097,0.012)$ \\
\hline $\begin{array}{l}\text { Current } \\
\text { drinkers }\end{array}$ & 0.259 & 0.027 & $(-0.020,0.074)$ & 0.253 & 0.028 & $(-0.020,0.075)$ & 0.235 & 0.029 & $(-0.019,0.077)$ \\
\hline
\end{tabular}




\begin{tabular}{|c|c|c|c|c|c|c|c|c|c|}
\hline \multicolumn{2}{|l|}{ No } & \multicolumn{3}{|l|}{ Ref } & \multicolumn{3}{|l|}{ Ref } & \multicolumn{2}{|l|}{ Ref } \\
\hline Yes & 0.000 & -0.056 & $(-0.086,-0.026)$ & 0.000 & -0.056 & $(-0.086,-0.026)$ & 0.000 & -0.056 & $(-0.086,-0.026)$ \\
\hline \multicolumn{10}{|l|}{$\begin{array}{l}\text { Marital } \\
\text { status }\end{array}$} \\
\hline Single & & Ref & & & Ref & & & Ref & \\
\hline Married & 0.226 & 0.081 & $(-0.050,0.212)$ & 0.221 & 0.082 & $(-0.049,0.213)$ & 0.231 & 0.080 & $(-0.051,0.211)$ \\
\hline Others ${ }^{b}$ & 0.620 & 0.033 & $(-0.100,0.167)$ & 0.620 & 0.034 & $(-0.099,0.169)$ & 0.605 & 0.035 & $(-0.098,0.168)$ \\
\hline \multicolumn{10}{|l|}{$\begin{array}{l}\text { Family } \\
\text { members }\end{array}$} \\
\hline $1 \sim 2$ & & Ref & & & Ref & & & Ref & Ref \\
\hline $3 \sim 4$ & 0.154 & 0.029 & $(-0.011,0.069)$ & 0.163 & 0.028 & $(-0.011,0.068)$ & 0.211 & 0.026 & $(-0.015,0.066)$ \\
\hline$\geq 5$ & 0.172 & 0.030 & $(-0.013,0.072)$ & 0.152 & 0.031 & $(-0.011,0.073)$ & 0.225 & 0.026 & $(-0.016,0.069)$ \\
\hline \multicolumn{10}{|l|}{$\begin{array}{l}\text { Income x } \\
\text { contracting } \\
\text { status }\end{array}$} \\
\hline $\begin{array}{l}\text { Q1 × } \\
\text { contracted }\end{array}$ & & & & 0.009 & 0.125 & $(0.032,0.218)$ & & & \\
\hline $\begin{array}{l}\mathrm{Q} 2 \times \\
\text { contracted }\end{array}$ & & & & 0.198 & 0.058 & $(-0.030,0.147)$ & & & \\
\hline $\begin{array}{l}\text { Q3 } \times \\
\text { contracted }\end{array}$ & & & & 0.719 & 0.017 & $(-0.074,0.107)$ & & & \\
\hline \multicolumn{10}{|c|}{$\begin{array}{l}\text { Educational attainment x } \\
\text { contracting status }\end{array}$} \\
\hline $\begin{array}{l}\text { Primary edu } \\
\text { below } \times \text { cont }\end{array}$ & $\begin{array}{l}\text { on or } \\
\text { ted }\end{array}$ & & & & & & 0.016 & -0.139 & $(-0.253,-0.026)$ \\
\hline $\begin{array}{l}\text { Junior } \\
\text { education } \times \\
\text { contracted }\end{array}$ & & & & & & & 0.008 & -0.167 & $(-0.292,-0.043)$ \\
\hline
\end{tabular}

Note: HRQOL: health-related quality of life; SES: socioeconomic status. SES: socioeconomic status.

a Q1 was the poorest and Q4 was the richest.

b Others include those who are divorced and widowed.

Table 4 The relationship between contracting status and HRQOL stratified by chronic patients with different household income and educational attainment in rural Shandong, China, 2018 


\begin{tabular}{|c|c|c|c|c|c|c|}
\hline \multirow[t]{3}{*}{ Characteristics } & \multirow{3}{*}{$\begin{array}{l}\text { EQ-5D-3L values } \\
\text { Coefficient } \\
(95 \% \mathrm{Cl})^{\mathrm{a}}\end{array}$} & \multicolumn{5}{|c|}{ EQ-5D-3L dimension } \\
\hline & & Mo & SC & UA & PD & $A D$ \\
\hline & & $\mathrm{AOR}^{\mathrm{b}}(95 \% \mathrm{Cl})$ & AOR $(95 \% \mathrm{Cl})$ & AOR $(95 \% \mathrm{Cl})$ & AOR $(95 \% \mathrm{Cl})$ & AOR $(95 \% \mathrm{Cl})$ \\
\hline \multicolumn{7}{|l|}{$\begin{array}{l}\text { Household } \\
\text { income }\end{array}$} \\
\hline \multicolumn{7}{|l|}{ Q1 } \\
\hline Uncontracted & Ref & 1.0 & 1.0 & 1.0 & 1.0 & 1.0 \\
\hline \multirow[t]{2}{*}{ Contracted } & $0.116^{\star \star}$ & \multirow{2}{*}{$\begin{array}{l}0.474^{*} \\
(0.244,0.921)\end{array}$} & \multirow{2}{*}{$\begin{array}{l}0.465 \\
(0.193,1.119)\end{array}$} & \multirow{2}{*}{$\begin{array}{l}0.57 \\
(0.305,1.080)\end{array}$} & \multirow{2}{*}{$\begin{array}{l}0.430^{\star \star} \\
(0.240,0.772)\end{array}$} & \multirow{2}{*}{$\begin{array}{l}0.460^{\star} \\
(0.227,0.929)\end{array}$} \\
\hline & $(0.039,0.194)$ & & & & & \\
\hline \multicolumn{7}{|l|}{ Q2 } \\
\hline Uncontracted & Ref & 1.0 & 1.0 & 1.0 & 1.0 & 1.0 \\
\hline \multirow[t]{2}{*}{ Contracted } & 0.049 & \multirow{2}{*}{$\begin{array}{l}0.442^{*} \\
(0.226,0.863)\end{array}$} & \multirow{2}{*}{$\begin{array}{l}0.489 \\
(0.199,1.201)\end{array}$} & \multirow{2}{*}{$\begin{array}{l}0.557 \\
(0.293,1.060)\end{array}$} & \multirow{2}{*}{$\begin{array}{l}0.733 \\
(0.433,1.241)\end{array}$} & \multirow{2}{*}{$\begin{array}{l}0.818 \\
(0.428,1.560)\end{array}$} \\
\hline & $(-0.134,0.112)$ & & & & & \\
\hline \multicolumn{7}{|l|}{ Q3 } \\
\hline Uncontracted & Ref & 1.0 & 1.0 & 1.0 & 1.0 & 1.0 \\
\hline \multirow[t]{2}{*}{ Contracted } & 0.013 & \multirow{2}{*}{$\begin{array}{l}0.827 \\
(0.398,1.697)\end{array}$} & \multirow{2}{*}{$\begin{array}{l}0.745 \\
(0.263,2.109)\end{array}$} & \multirow{2}{*}{$\begin{array}{l}0.889 \\
(0.444,1.778)\end{array}$} & \multirow{2}{*}{$\begin{array}{l}0.934 \\
(0.525,1.661)\end{array}$} & \multirow{2}{*}{$\begin{array}{l}0.881 \\
(0.409,1.900)\end{array}$} \\
\hline & $(-0.051,0.076)$ & & & & & \\
\hline \multicolumn{7}{|l|}{ Q4 } \\
\hline Uncontracted & Ref & 1.0 & 1.0 & 1.0 & 1.0 & 1.0 \\
\hline \multirow[t]{2}{*}{ Contracted } & -0.002 & \multirow{2}{*}{$\begin{array}{l}0.602 \\
(0.289,1.257)\end{array}$} & \multirow{2}{*}{$\begin{array}{l}0.708 \\
(0.219,2.290)\end{array}$} & \multirow{2}{*}{$\begin{array}{l}0.286^{* \star} \\
(0.116,0.698)\end{array}$} & 1.208 & 1.144 \\
\hline & $(-0.063,0.058)$ & & & & & \\
\hline $\begin{array}{l}\text { Educational } \\
\text { attainment }\end{array}$ & & & & & & \\
\hline Primary educat & below & & & & & \\
\hline Uncontracted & Ref & 1.0 & 1.0 & 1.0 & 1.0 & 1.0 \\
\hline Contracted & 0.037 & 0.587 & 0.569 & 0.525 & 0.888 & 0.727 \\
\hline & $(-0.004,0.077)$ & $(0.395,0.873)^{n}$ & $(0.334,0.972)^{n}$ & $(0.351,0.786)^{\wedge}$ & $(0.631,1.249)$ & \\
\hline Junior educatio & & & & & & \\
\hline Uncontracted & Ref & 1.0 & 1.0 & 1.0 & 1.0 & 1.0 \\
\hline Contracted & 0.001 & 0.617 & 0.523 & 0.803 & 0.987 & 1.623 \\
\hline & $(-0.063,0.065)$ & $(0.217,1.012)$ & $(0.031,2.095)$ & $(0.000,1.172)$ & $(0.579,1.685)$ & $(0.1 / 0,0.092)$ \\
\hline Senior educatio & above & & & & & \\
\hline Uncontracted & Ref & 1.0 & 1.0 & 1.0 & 1.0 & 1.0 \\
\hline Contracted & $\begin{array}{l}0.236 \\
(0.095,0.379)^{\star \star \star}\end{array}$ & $\begin{array}{l}0.234 \\
(0.051,1.086)\end{array}$ & $\begin{array}{l}0.215 \\
(0.017,2.666)\end{array}$ & $\begin{array}{l}0.392 \\
(0.099,1.546)\end{array}$ & $\begin{array}{l}0.187 \\
(0.064,0.545)^{\star *}\end{array}$ & $\begin{array}{l}0.124 \\
(0.212,0.728)^{*}\end{array}$ \\
\hline
\end{tabular}

Note: HRQOL: health-related quality of life; MO: mobility; SC: self-care; UA: usual activity; PD: pain/discomfort; AD: anxiety/depression.

$P$-values with statistical significance: ${ }^{*} P<0.05,{ }^{* \star} P<0.01,{ }^{* \star} P<0.001$.

Adjusted for age, gender, marital status, sports participation, drinking status, multiple chronic diseases, family members.

a EQ-5D-3L utility values, Regression coefficient based on a Tobit regression fully adjusted for 
${ }^{b}$ Odds ratio based on a multivariate logistic regression fully adjusted for

Page 15/15 